\title{
VARSÓVIA 1949: RECONSTRUÇÃO OU NASCIMENTO DE UMA NOVA CIDADE? ${ }^{1}$
}

\author{
PIERRE GEORGE
}

A nova Varsóvia que se edifica rapidamente conservará as características arquiteturais nacionais da velha capital polonesa; no entanto, ela será ao mesmo tempo uma cidade nova devido à disposição das unidades urbanas e à concepção da vida dos cidadãos.

No lugar da cidade oficial e mercante de antes da guerra, edifica-se um centro funcional reunindo administração, serviços públicos, instituições culturais e grandes lojas associadas a um pequeno número de ilhotas de habitação. No exterior de um anel verde, constroem-se os bairros residenciais intercalados às zonas industriais.

A capital polonesa tinha 1.300 .000 habitantes na véspera da segunda guerra mundial. Lá existiam alguns milhares de cadáveres enterrados entre ruínas empilhadas, no momento da Liberação, em 17 de fevereiro de 1945. Essas destruições se elevariam a 85\%; o número de pessoas que encontraram a morte em Varsóvia entre 1939 e 1945 foi estimado em torno de 800.000.

Alguns quarteirões, especialmente a cidade velha e o gueto, situados no norte da aglomeração, estavam completamente arrasados. As ruas, obstruídas pelos escombros dos imóveis em colapso, confundem-se com as ilhotas de casas esmagadas enquanto parte das fachadas habitadas que restaram de pé não fazem inveja ao antigo traçado arquitetônico. As redes de iluminação, de distribuição de água, de esgoto deixaram de existir.

$* * *$

\footnotetext{
${ }^{1}$ Texto publicado originalmente em Population, revista trimestral do Instituto Nacional de Estudos Demográficos, n. 4, outubro-dezembro, 1949.

Tradução enviada por Breno Viotto Pedroza.
} 
Seria possível, ao preço de um enorme esforço, restaurar a capital polonesa de 1939, porém se restauraria uma cidade antiga encontrada debaixo de areia e cinzas. Mas, uma cidade não é somente um conjunto monumental. Ela é, antes de tudo, uma realidade funcional, uma residência humana respondendo às necessidades econômicas e políticas, abrigando um complexo social, cujo conteúdo varia de acordo com o desenvolvimento relativo das diversas funções urbanas.

$\mathrm{Na}$ Europa, as modificações maiores desse conteúdo foram efetuadas no curso do último século e relacionam-se com o desenvolvimento da indústria e da economia capitalista. Elas determinaram as transformações da paisagem urbana, consistindo, sobretudo, na adjunção das cidades antigas, resultante de um sistema anterior de funções urbanas, aos novos bairros. Essas transformações efetuaram-se no quadro do liberalismo e só obedeceram a algumas leis geográficas e econômicas, especialmente, à da busca de terrenos planos ligados aos grandes eixos naturais de comunicação e, em particular, as vias hídricas, negociadas a melhores preços para a instalação de estabelecimentos industriais. A construção de imóveis foi objeto de concorrência e especulações múltiplas. Isso é o resultado da fusão de estabelecimentos industriais, de casas e bairros desordenados, estranhos a todo plano de conjunto e de uma densidade ocupacional ainda maior do que o elevado preço da terra. As funções de distribuição indispensáveis aos serviços públicos elementares estão localizados empiricamente entre as protuberâncias [excroissances] dessas cidades sem que todas as necessidades sejam uniformemente e racionalmente atendidas.

A anterioridade das cidades e suas relações com as formas econômicas e sociais dos séculos XIX e XX aumentaram a confusão da vida urbana. Os imóveis e bairros mudaram de destinação e de conteúdo econômico e social. As "cidades velhas" dos padres, dos pequenos comerciantes e artesãos transformaram-se em bairros de negócios no centro das novas cidades, associando bancos e estabelecimentos comerciais às catedrais e aos velhos mercados, ao passo que os bairros sem glória histórica e sem alegria humana estendiam-se ao redor.

Varsóvia não escapara da linha geral desses processos. Mas, ao invés de pertencer ao tipo de cidades de desenvolvimento circular como Paris, Berlim ou Praga, ela é caracterizada historicamente pelos deslocamentos do centro de atividade ao longo de um eixo Norte-Sul e por um desenvolvimento urbano linear correspondente. Acerca dessa diferença, o crescimento moderno de Varsóvia é muito rápido, uma vez que ele se 
efetuou essencialmente entre 1919 e 1939, partilhando da confusão e do amontoamento do desenvolvimento urbano da Europa contemporânea. Algumas tendências originais, no entanto, são afirmadas no passar desse período, notadamente, o crescimento pelo desenvolvimento de satélites de residência na periferia imediata da cidade, dos satélites industriais - de produção e de residência - nos arredores. Crescimento esse, iniciado por uma segregação econômica e social de causas múltiplas (assim como, por exemplo, a tendência da classe dirigente de relegar os trabalhadores para fora da cidade, que organizam as cooperativas de trabalhadores para habitação na periferia). Varsóvia, em 1939, evoluía para um tipo urbano em constelação.

A liberação da Polônia é acompanhada de uma transformação profunda da estrutura econômica e política do Estado. A reconstrução de Varsóvia, como a reconstrução de toda Polônia, fez-se objeto de uma planificação que leva em conta as novas formas de organização e desenvolvimento econômico, político e social. O empirismo do crescimento urbano do período anterior à guerra opõe-se à planificação urbana, guiada pelas perspectivas da construção de uma economia socialista. Portanto, não se tem aí uma reconstrução no sentido estrito do termo, mas diante do quadro das liberdades materiais que permitiram a trágica desconstrução da cidade, existe a concepção e realização de uma nova cidade. Essa cidade deve permanecer bastante fiel às suas tradições para ser o símbolo da continuidade e ser muito desprendida do passado para responder à imagem original e às necessidades administrativas, econômicas e sociais de uma capital socialista. Mensura-se assim a amplitude do problema colocado aos urbanistas e o interesse nessa experiência única na Europa (além daquelas da URSS) da criação de uma cidade muito grande, específica de um sistema econômico e social novo.

1. Os dados da geografia e da história: (fig. 1 a posição de Varsóvia) Varsóvia é uma cidade-ponte situada em um sítio onde a grande rota lesteoeste, da Europa do Norte, se serve sucessivamente dos canais do Bug inferior e da Varta, atravessando o rio Vistula (fig. 1). O desenvolvimento da cidade foi guiado pela dissimetria do relevo do vale do Vistula. O sítio de Varsóvia evoca o de Kiev e de várias outras cidades da margem ocidental dos rios da Europa oriental. A cidade prende-se ao alto terraço da 
margem esquerda, que mantém de 25 a 30 metros de altura, seguidos de sítios onde há uma estreita planície baixa e fechada, e contendo um tálus abrupto que marca seu limite com o rio. Na margem direita, somente uma planície baixa se estende a perder de vista. O crescimento da cidade se efetuou perpendicularmente ao eixo de circulação, transpondo o Vistula, ao longo da borda do platô. Até o final do século XIX, a originalidade e o caráter pitoresco de Varsóvia residiam no recorte da silhueta da cidade, dominada por suas torres barrocas que se alongam no cume da colina e emergem das brumas que se prolongam sobre o Vistula e sobre os lagos dos parques.

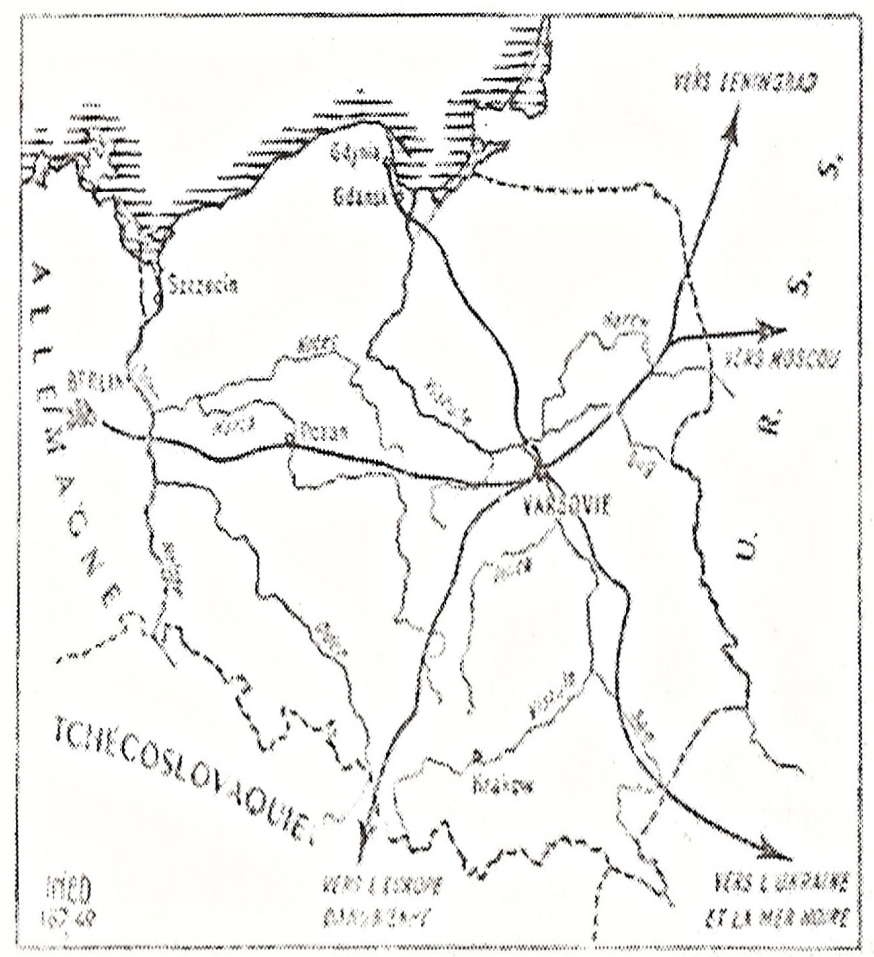

Fig. 1. - I position de Varsonke. 
A cidade velha - a cidade gótica e a cidade barroca (Stare Miasto) estava situada no noroeste da atual ponte de Praga. No sudeste, o palácio real e o "eixo saxão" representavam uma tentativa de fixação, no século XVIII, de um eixo urbano no sentido leste-oeste. Apesar dessa tentativa e mesmo com um início anterior de desenvolvimento urbano no sentido norte durante a Idade Média (Nowè Miasto), a cidade propriamente dita estendeu-se, sobretudo, na direção sul, nos séculos XIX e XX, enquanto os anexos industriais ou residenciais cresceriam no seu entorno (fig. 2).

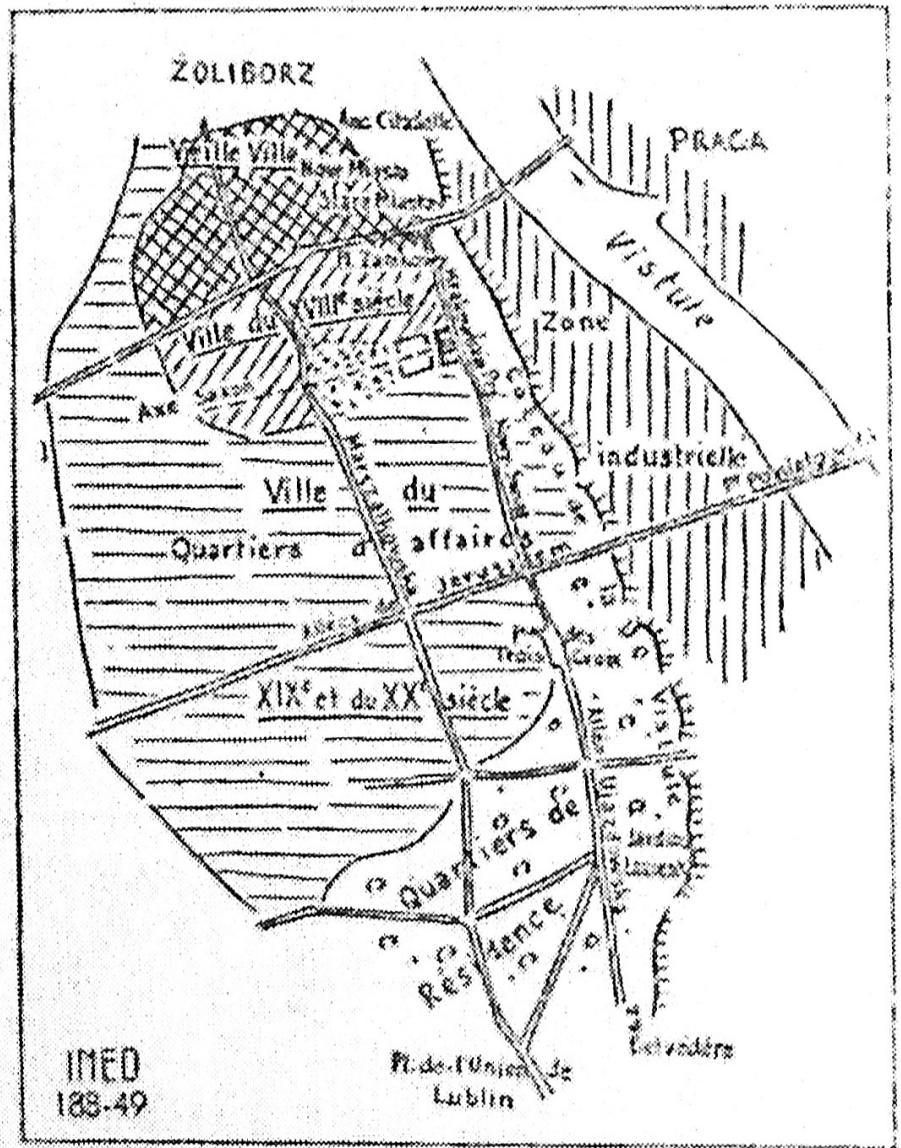

Fig. 2. - La ville do Varsovie en 1938 
A cidade comercial e burguesa progrediu ao longo dos eixos nortesul: Marszalkowska, Nowy-Swiat, contornando, pelo oeste até a União de Lublin, o bairro aristocrático dos palácios e dos jardins (Lazienki, Belvédère), dos ministérios e das embaixadas; composta entre as árvores dos parques e as avenidas ao longo da colina do Vistula, a partir da Ponte Poniatowski e da praça das Três-Cruzes. O traçado geral era geométrico, porque o desenvolvimento urbano foi dominado pelas duas direções maiores ortogonais: a do eixo norte-sul e a das vias transversais cujas principais ruas conduziam às pontes do Vistula.

Entretanto, o panorama de Varsóvia tornou-se feio no século XIX e, sobretudo no XX, pelas especulações que focaram a aquisição de terrenos de baixo custo para a construção de fábricas e bairros operários. As fábricas e os bairros operários invadiram a faixa de terras baixas que separam o Vistula das colinas. As chaminés das fábricas, as silhuetas das casas sem beleza, implantadas em terra úmida, e o nevoeiro engrossado pela fuligem mascaram e desbotam a beleza histórica de Varsóvia. A margem direita do rio traz consigo, por sua vez, estabelecimentos industriais e "colônias de trabalhadores" pobres. Ao redor de Varsóvia aparecem, depois de 1919, as periferias industriais, algumas colônias monótonas e uniformes e outras, testemunhando os maiores avanços das condições modernas de habitação. Isso ocorre especialmente em Zoliborz onde se devolverá a experiência da cooperativa de habitação. Percebe-se a rapidez dessa transformação urbana que atinge a um número significativo da população, no passar do último século: 145.000 habitantes em 1850, 900.000 em 1914, 1.200 .000 em 1930 e 1.300 .000 em 1938.

A cidade se apresentava como um complexo urbano heterogêneo compreendendo:

a) a cidade velha (no sentido amplo do termo), Stare Miasto e Nowè Miasto, desde a cidadela até o Palácio Real. Esse conjunto de construções, envolto em torno de ruas estreitas, guarda a maior parte dos monumentos antigos da cidade. Ele estava povoado por uma massa densa de pequenos comerciantes, artesãos, funcionários e trabalhadores, compreendendo em particular a população judia, estimada em 400.000 indivíduos.

b) a cidade burguesa, centro político e centro de negócios, no sul, diferenciando-se em quarteirões de comércio e bancário, no norte e oeste, e em quarteirão de luxo e de residência diplomática no sudeste. Essa cidade burguesa, separada da precedente pelos vastos espaços descobertos ou arborizados do eixo saxão, representa as novas formas econômicas e sociais em oposição aos símbolos do período feudal, atribuídos à cidade 
velha. O desenvolvimento de Varsóvia foi tão brusco que não houve fusão, mas uma transição entre uma e outra com a coexistência lado a lado de espécies urbanas pertencentes a duas épocas e a dois sistemas econômicos e sociais diferentes.

c) os bairros e as periferias da indústria, de habitação operária, dispostos perifericamente, sendo os mais antigos nas duas margens do Vistula e os mais recentes, no norte (Marymont, Zoliborz), no oeste (Kolo, Ochota) e no sul (Mokotow).

d) as aglomerações satélites desenvolvidas, geralmente, seguindo o tipo cidade-fábrica em um raio de $50 \mathrm{~km}$ ao redor da capital (Wlochy, Pruszkow, Rembertow e no extremo limite da zona de influência de Varsóvia, Zyrardow...).

Esse complexo desenvolvido muito velozmente e sem plano de conjunto estava deslocado, estripado, quase completamente destruído em 1945. Apesar da urgência da reconstrução de edifícios capazes de organizar uma população que cresceu rapidamente, tendo em vista o estado lamentável da cidade (12.000 habitantes em janeiro de 1945, $48.000 \mathrm{em}$ abril, 200.000 no final do ano, 600.000 no final de 1948), o Governo e a administração da cidade julgam indispensável subordinar a reconstrução definitiva à execução de um plano, correspondente às novas funções da cidade, capaz de fazer de Varsóvia a capital racional de uma democracia popular.

2. O novo urbanismo. A função do centro de negociações nacionais e internacionais, o lugar de residência da classe dirigente e de todo elemento parasitário que se esforça para viver em sua sombra é substituída pela capital de uma república popular, construindo uma nova economia no contexto dos planos. A função essencial da cidade torna-se a de uma capital política e administrativa (no sentido mais amplo do termo, correspondendo a uma multiplicidade de funções administrativas de um Estado de economia planificada tendendo ao socialismo) e, também, de capital cultural. Podia-se, sobre essas bases, conceber uma capital à maneira de Washington ou de Camberra, onde as atividades dirigentes do Estado seriam exclusivas perante toda forma de vida econômica.

Isso teria apartado a cidade de todo o seu passado de cidade trabalhadora, que lhe dá um conteúdo social especial e excepcional, negligenciando um importante fator permanente de desenvolvimento urbano: o grande cruzamento de rotas leste-oeste e norte-sul. Varsóvia 
unirá, portanto, sua função política e econômica (trânsito, distribuição, transformação de produtos).

Essas duas funções poderiam ser concebidas como geograficamente distintas. Nesse caso, se realizará a edificação de duas cidades gêmeas. Entretanto, contrariamente, seu emaranhamento total faria nascer uma cidade indiferente sem nenhum zoning [zoneamento]. Uma solução intermediária foi escolhida. Ela inspira-se em alguns princípios diretivos e tende a alguns objetivos fundamentais:

a) a restauração e valorização de fatores estéticos naturais da cidade e a reconstrução, com uma ambientação conforme ao seu destino e estilo, dos edifícios históricos destruídos pela guerra;

b) a concentração geográfica dos edifícios e serviços públicos assegurando grandes comodidades para o trabalho político e administrativo;

c) a supressão de toda segregação social entre os bairros residenciais através da normatização das condições de habitação no melhor nível possível, atualmente, construindo bairros de habitação de um tipo único (a normatização não deve ser interpretada como implicando a uniformidade e monotonia).

d) a abertura do espaço urbano, introduzindo em vários lugares parques e jardins, e assegurando uma circulação rápida nas grandes artérias corrigidas pela associação íntima dos locais de habitação e edifícios de serviços, normalmente ligados pelas necessidades elementares da vida cotidiana de uma civilização moderna, no interior de unidades residenciais racionais.

A primeira noção a definir, antes do começo da aplicação dos princípios, era a superfície e o conteúdo numérico. A cidade de 1938 cobria 12.000 hectares. Ela era muito desigualmente ocupada: a cidade velha tinha mais de 500 ou mesmo mais de 700 habitantes por hectare, enquanto os quarteirões do sudeste tinham de 10 a 100. Com 1.200.000 habitantes, a densidade média era de 100 habitantes por hectare. A ocupação média era maior que a de Berlim (87.500 ha. para 4 milhões de habitantes) e comparável à da grande Paris (Sena, 48.000 ha. Para, aproximadamente, 5 milhões de habitantes).

O plano visa, ao mesmo tempo, mobilizar uma superfície vasta para a repartição de diferentes elementos constitutivos da cidade e controlar seu crescimento, de forma a não ultrapassar o número de 1.000.000 habitantes em 1955 e atingir, ao máximo - nas condições econômicas e políticas 
presentes - cerca de 1.200.000 habitantes. A grande Varsóvia, contando as cidades satélites poderia atender, expressivamente, ao dobro dessa população, se repartida em um raio de $50 \mathrm{~km}$. O espaço urbano propriamente dito cobrirá 180.000 hectares. O nó principal iguala-se em poucos aspectos à Varsóvia antiga, pois ocupará 14.000 hectares, mas contará com uma população bem inferior àquela da cidade anterior à guerra, porque as construções serão menos densas e, também, porque os edifícios administrativos ou de interesse coletivo ocuparam uma ampla área, e o número de residentes será automaticamente reduzido.

3. A "capital" e os bairros centrais. O centro da cidade será constituído por um conjunto envolto por um vasto semicírculo arborizado, que passa pelo Vistula, indo da antiga cidadela no norte até o Belvédère no sul e segue um diâmetro nor-nodeste, sul-sudeste, de 6 km (fig. 3).

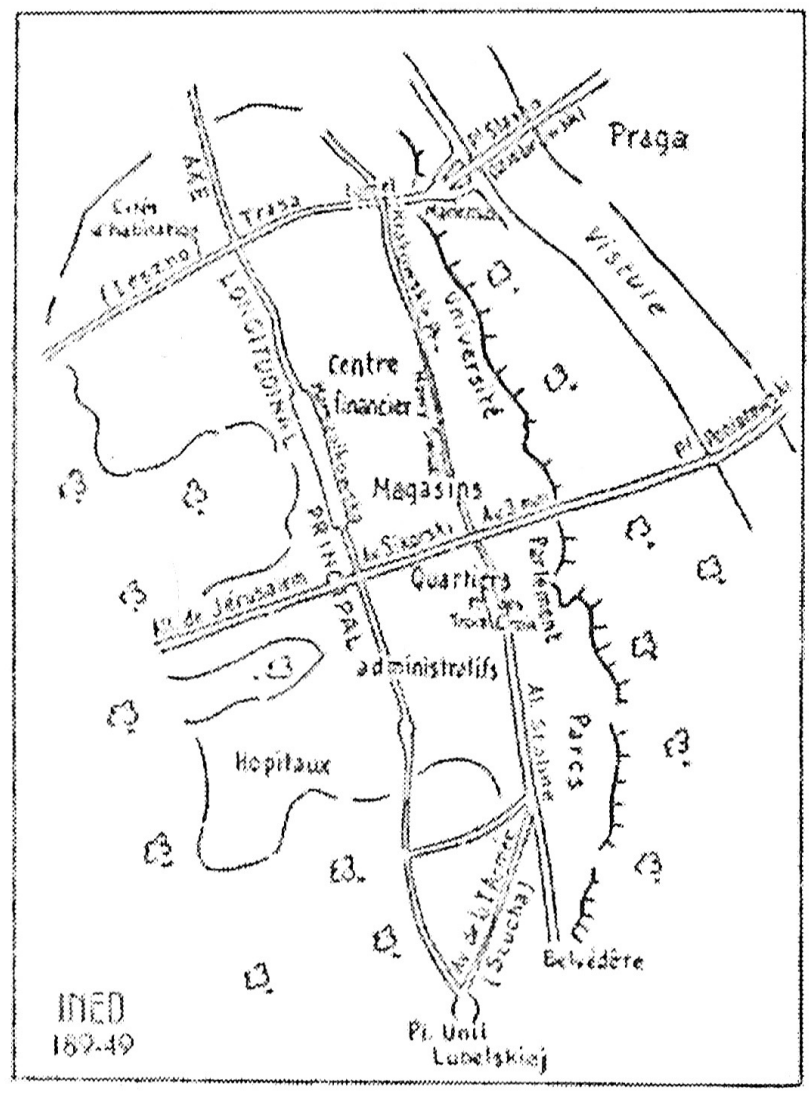

Fig. 3. - Le "Zoning " du centre de la villes. 
a) O traçado - o plano das ruas não sofreu modificação profunda. A cidade permanecerá em tabuleiro, alongada no eixo norte-sul. A cidade baixa, na margem esquerda do Vistula - bairros industriais -, foi escolhida para desaparecer progressivamente de maneira a liberar a colina, formando o elemento maior do panorama arquitetural. Por outro lado, as vias principais devem ser abertas para a circulação transurbana e intraurbana contemporânea. Devem ser substituídas as grandes artérias de antigamente por grandes avenidas, uma vez que lhes faltam amplitude. Nesse sentido, dois grandes canteiros foram abertos: um, para atribuir um alargamento à ponte Slasko-Dabrowski, permitindo o transporte transurbano para evitar o centro da cidade e outro, para ampliar o eixo longitudinal.

Por enquanto, a primeira edificação, já realizada de um complexo arquitetural espetacular, obra do urbanista Sygalin, a Trasa leste-oeste, é uma larga via que corta a encosta da margem do rio, partindo da esquerda para direita através de um túnel de 195 metros, que passa debaixo do velho bairro restaurado da praça Zamkowy, se encontra com a antiga rua Leszno (avenida Gen. Swierczewski) em Wolska, onde se iniciam os caminhos para Poznan e Lodz. A realização da Trasa foi concluída no início do verão de 1949, o que é na visão de alguns o laboratório do novo urbanismo de Varsóvia. A valorização da colina por um conjunto monumental, a construção de bairros de 2.500 habitantes na borda da ponte, inspirado na arquitetura polonesa do século XVIII, fazem com que Mariensztat prefigure o aspecto que apresentará a cidade ao longo do Vistula.

A Trasa foi dobrada para conter uma ferrovia paralela, situada um pouco mais ao norte e que está sendo ampliada. $O$ transporte de passageiros da periferia entre Varsóvia e Praga efetua-se por outra transversal ferroviária que cruza o Vistula no norte da ponte Poniatowski e passa, igualmente, por um túnel sob a cidade.

$\mathrm{O}$ planejamento do eixo longitudinal foi assegurado pelo prolongamento no sentido norte, até a saída da cidade em Marzalkowska, e que passa pelas ruínas do gueto, estabelecido pelos Alemães para abrigar o antigo bairro judeu, com o alargamento dessa artéria para 120 metros no centro da cidade entre o eixo saxão e a rua Bartoszka, não distante da avenida Sikorski (um dos elementos da transversal meridional saída da ponte Poniarowski, uma das maiores vias da velha Varsósia que foi restabelecida nas suas antigas funções). A segunda artéria longitudinal da antiga cidade: Krakowskie Przedmiescie - Novy Swiat - Stalina - I Armija, foi restaurada em todo seu percurso e flanqueia, no centro da cidade, uma via paralela bem desobstruída (Szpitalna Krusza). 
b) Um zoning moderado - o centro da cidade não abrigará mais que 100.000 habitantes segundo a previsão dos urbanistas. Ele será construído conforme o plano, com menos da metade do número de pessoas que residem atualmente nos edifícios que escaparam da destruição ou que estão sendo provisoriamente utilizados como habitação. O lugar dos edifícios públicos será, portanto, considerável nessa parte da cidade, mas não serão exclusivos.

Os quarteirões situados imediatamente ao sul dos jardins da Saxônia, que já compreendiam vários estabelecimentos bancários antes da guerra, se tornarão o centro financeiro da Polônia. Construíram-se, entre Nowy-Swiat e a praça de Napoleão, imensos edifícios do banco do Estado, ao lado da Caixa econômica comum e uma série de grandes prédios destinados a administrar os diversos serviços de financiamento e de crédito especializado. Um pouco mais longe, no sentido sul, próximo à intersecção entre Nowy-Swiat e a alameda do General Sikorski edifica-se o alto edifício de grandes lojas de varejo, apesar de, nas ruas vizinhas e notadamente na longa Nowy-Swiat, o comércio privado de varejo rivalizar com engenhosidade para deter o cliente diante de suas novas vitrines.

$\mathrm{O}$ alto da encosta dominando o Vistula está especialmente reservado aos prédios da Universidade, aos Institutos científicos e aos Museus no norte e aos edifícios políticos mais ao sul, notadamente ao Parlamento, reconstruído nos jardins Frascati, que compreendem as salas de sessões, os prédios administrativos e um grande hotel para a estadia dos deputados. É possível definir uma "zona política" atrás do Parlamento que reúne outros edifícios, casas de residência, de comércio, uma grande parte dos ministérios, os serviços centrais dos grandes partidos políticos, os jornais e as embaixadas. Elas se estendem no sudoeste entre a colina do Vistula, na alameda de 3 de maio (que se prolonga na Gen. Sikorski) e Marszalkowska. Mas, esse belo bairro, ventilado pelas grandes avenidas e parques que termina ao sul, ao longo das quadras da residência presidencial (o Belvédère) não agrupam e não agruparão, sistematicamente, todos os ministérios e todos os serviços públicos. Reciprocamente, a função política não exclui outras atividades.

Um zoneamento sistemático teria feito do centro de Varsóvia uma cidade abstrata onde a atividade somente manteria o entretenimento noturno próximo dos teatros, das salas de concerto, dos clubes e hotéis. Esse zoneamento sistemático não pareceu nem possível, nem desejável. $\mathrm{O}$ respeito aos direitos dos comerciantes e artesãos de restabelecer suas instalações nos lugares que eles ocupavam anteriormente, ou de se mudar a 
sua escolha, provoca a associação, ao longo das grandes ruas muito frequentadas, da função comercial e residencial com funções administrativas, políticas ou culturais. Mas se, de um lado, o período de transição do capitalismo para o socialismo deixa para trás as pequenas empresas comerciais e artesanais, na nova Varsóvia pareceu desejável, por outro lado, abrir o capital à moradia proletária. É útil acomodar os funcionários dos ministérios, do banco ou das lojas na proximidade de seus lugares de trabalho, portanto, no centro, mas preferiu-se agrupar os trabalhadores e funcionários para evitar uma segregação profissional que não mantivesse um espírito de classe ou ao menos de categoria social. De uma maneira geral, os bairros de moradia construídos no centro ou na borda da cidade, sobre as ruínas do gueto ou em torno da Praça da União de Lublin, são destinadas a acolher os habitantes de todas as profissões. Contudo, para as comodidades particulares ou circunstanciais, se edificou um bairro de funcionários e se construiu um bairro para o ministério dos negócios estrangeiros, que compreende a moradia do pessoal e um hotel para os viajantes diplomáticos.

O zoneamento no interior do centro da cidade permanece, portanto, muito sutil e evoca as correções sistemáticas. Ele é mais rigoroso quanto à repartição das unidades industriais e residenciais ao redor da "capital".

4. Bairros de residência. $\mathrm{O}$ plano de reconstrução reserva dois setores para a indústria: um, sobre a margem direita do Vistola, embocadura entre a cidade e Praga, em Zeran, na proximidade de um porto fluvial a ser construído na margem direita do Vistula, e outro, a oeste da cidade em Wola, junto à futura estação das mercadorias.

Zeran será o lugar de implantação das indústrias pesadas e das indústrias inadequadas ao espaço residencial (indústrias químicas especialmente). Wola possuirá as fábricas das indústrias leves. Fora dessas duas zonas industriais principais, as fábricas poderão ser estabelecidas a oeste de Sluzew, em torno de Praga e ao longo da transversal ferroviária norte entre Zoliborz e Kolo, nos pequenos territórios reservados para isso (fig. 4). 


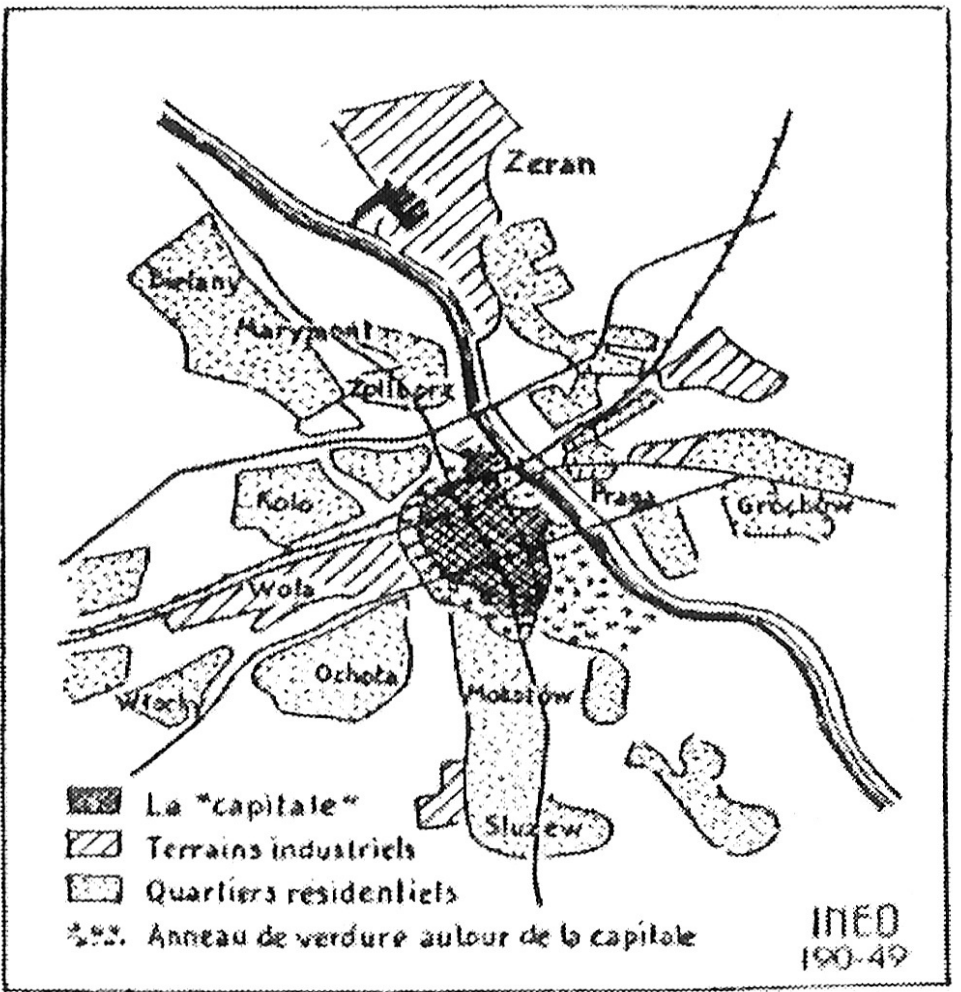

Fig 4. Le "Zonion " des quartiers de resdenre ol des lerrains industriels.

Todo o resto da zona periférica urbana está reservado para a função residencial e deve assegurar a moradia e a vida social da população fixada pelas atividades terciárias da capital ou pelas atividades industriais de seus anexos.

Antes da guerra, a construção de imóveis de habitação era, em grande parte, responsabilidade do setor privado, sendo que uma parte, menos importante quantitativamente, porém muito interessante pelos seus mecanismos financeiros e sociais, era feita pela cooperativa habitacional de Varsóvia. Certamente o princípio cooperativo, no que diz respeito à 
moradia, como em outros aspectos, pode encontrar sua plena aplicação na democracia popular. Mas, o retorno ao sistema de cooperativa habitacional e a sua generalização na escala da reconstrução dos bairros residenciais de Varsóvia exigiria uma considerável economia da população que perderam tudo e devia direcionar de imediato a totalidade de seus recursos na renovação de seus bens menores. Eles exigiram a reconstituição de um aparelho administrativo considerável que não podia substituir os serviços de urbanismo e de reconstrução da cidade, e cuja missão é a de coordenar as iniciativas e de assegurar o funcionamento de todos os serviços indispensáveis à vida normal de todo o organismo urbano. A centralização de todas as operações de construção é a prova da rapidez de ação com que contam aquelas numerosas famílias que vivem em acampamentos provisórios desde 1945. No quadro cronológico das perspectivas do plano de seis anos, a construção permanecerá uma função do Estado, sem que este precedente signifique que não há planos para o futuro. A iniciativa individual não está excluída, com a condição de que ela se submeta ao plano de urbanismo. A importância dos créditos necessários e a atribuição prioritária das disponibilidades dos bancos nacionalizados aos canteiros de utilidade pública e do Estado reduz, de fato, as construções de galpões fora da zona urbana propriamente dita.

A fim de não piorar o problema extremo das comunicações intraurbanas e de facilitar o acesso dos grupos populacionais numericamente importantes aos centros sociais elementares da cidade e dos bairros, a fórmula de bairro com imóveis de quatro a cinco andares com moradias múltiplas foi escolhida, com a exclusão de bairros de casas individuais, mais próprios às aglomerações menos importantes.

Os bairros de habitação são construídos, tomando como base os princípios e métodos testados antes da guerra pela cooperativa habitacional, com o respaldo de numerosos estudos, apesar de sua generalização e seu aperfeiçoamento. A ideia geral é a de uma hierarquia e de um enquadramento das unidades residenciais: imóvel, bairro elementar, bairro, cidade.

O bairro elementar forma um agrupamento autônomo provido de instalações sociais e culturais respondendo às necessidades fundamentais de um grupo humano. Ele comporta um determinado número de construções, que podem ser, elas mesmas, possuidoras de alguns serviços indispensáveis. Uma creche e um jardim de infância parecem necessários para um grupo de uma centena de moradias, mesmo que se possa considerar uma escola elementar para 500 casas e um centro escolar 
complexo (escolaridade completa do primeiro grau e primeiros anos de ensino médio) para 2.000 a 2.500 casas. O quarteirão elementar com seu centro econômico, social e cultural (grupo escolar, salas de reunião e de espetáculo, cinema, clube, clínica médica, lojas cooperativas e lojas privadas) parece dever ser limitado a um grupo, podendo abrigar cerca de 10.000 pessoas em um raio de 500 metros ao redor do centro geométrico do conjunto construído. Com seu centro coletivo ("ágora" de H. e S. Syrkus), ele constitui uma pequena cidade dentro da grande. Ele possui as instalações necessárias para satisfazer as necessidades imediatas e cotidianas, mas vive a vida da cidade e deve manter sua atenção no centro social e cultural ("ágora") da capital. Essa ideia sugeriu à Sra. e ao Sr. Syrkus que o centro social e cultural de cada bairro deve ser mais exterior do que interior, de maneira a ser ligado facilmente ao centro urbano principal pelas vias de comunicação radiais em torno da cidade. Os diferentes centros sociais dos quarteirões nas margens dessas vias de comunicação constituem uma semeadura descontínua ou semicontínua de instalações de interesse coletivo e dão às vias de comunicação ditas "radiais" um caráter original, por ligar as pequenas ruas que servem ao interior dos bairros. Elas contribuem para constituir a armadura social do bairro, que é, organicamente, um grupo de quarteirões podendo ultrapassar 100.000 habitantes. A importância numérica do bairro evoca, ao contrário, a presença de um centro social de escala superior, podendo comportar um grupo escolar diferenciado que pode assegurar o exercício da escolaridade completa do segundo grau em todas as orientações previstas, um centro politécnico, um estádio, os serviços administrativos e os de segurança.

$\mathrm{Na}$ escolha dos tipos de construção, esforça-se para manter em harmonia diversas considerações: normatização dos tipos de construção, homogeneização das condições de moradia no nível mais elevado possível, diferenciação dos aspectos exteriores dos quarteirões e das casas e, também, das moradias.

A rapidez do rebaixamento do preço de realização da construção e a sua realização com uma mão de obra em que a proporção de técnicos e de trabalhadores qualificados é próxima do mínimo, em razão da enorme demanda da mão de obra da indústria da construção, estão em ligação direta com a normatização. Isso não deveria ser discutido. Ela também se harmoniza com a vontade de uniformizar as condições de moradia, introduzindo em todas as novas construções as mesmas formas de comodidade, de conforto e estética. Mas, ela mostra o perigo de favorecer 
uma multiplicação de imóveis em série, marcando os quarteirões residenciais com uma uniformidade assustadora.

Os arquitetos, portanto, pensam em fazer surgir uma variedade de paisagens urbanas com a modificação da disposição dos elementos normatizados da construção. É possível multiplicar assim o número de tipos de imóveis, equivalentes intrinsecamente pelo seu conteúdo nas unidades materiais de base. Os urbanistas utilizam as formas do terreno para dividir diferentemente os grupos de edifícios, variando a disposição das dependências sociais, dos jardins e dos espaços de lazer. Tal quarteirão resulta em uma forma circular (uma parte de Zoliborz), com suas unidades repartidas, seguindo o plano ortogonal que evoca um problema de ruas cruzadas (Mokotow). Porém, evitam-se as grandes sequências de imóveis em linha retilínea (algumas tentativas dessa ordem haviam sido feitas antes da guerra). Aqui, as fachadas são retas, iluminadas por grandes vidraças; em outros lugares, são cavados nichos, balcões cercados e terraços expostos.

Existem ainda muitos canteiros entre os grupos de casas já terminadas para que se possa desenvolver uma imagem de síntese dos diversos quarteirões residenciais. Mas, mesmo no terreno plano, cada quarteirão, até o presente momento, tem sua própria fisionomia.

Em todo caso, a originalidade do quarteirão não repousa mais sobre a composição de sua população. É provável que, enquanto o projeto de planejamento de Praga e de Zeran estiver realizado, a margem direita do Vistula abrigue mais trabalhadores do que a esquerda; mas a fórmula cidade-fábrica não foi aplicada em Varsóvia. As representações das diversas profissões serão vizinhas no mesmo quarteirão. Estima-se, por um lado, que os grandes imóveis residenciais assegurem um anonimato total a seus ocupantes, muito mais completo que o loteamento de galpões. A vida coletiva, por outro lado, pediu para se desenvolver em torno do centro social e cultural, fora da moradia onde funciona especificamente a vida individual e familiar. Ela foi concebida de forma a assegurar o máximo de comodidades para uma superfície dada e ser proporcional ao número de pessoas de cada família. A moradia padrão para um jovem casal com uma criança é composta de dois quartos e cozinha, com banheiro completo, cobrindo de 40 a 50 metros quadrados. Porém, existe um número muito grande de variantes na disposição dos cômodos com a finalidade de responder à diversidade das necessidades segundo a composição das famílias. 
A associação, no interior dos mesmos quarteirões e dos mesmos bairros, de pessoas que exercem profissões diferentes supõe a circulação cotidiana de um número muito grande de habitantes nos diversos setores da atividade profissional especializada. A capital atrai os funcionários, os empregados, os estudantes. Essa atração anima a circulação nas vias radiais. Os deslocamentos dos trabalhadores são mais complicados e podem utilizar, por sua vez, as vias que unem diversas unidades periurbanas umas às outras.

O planejamento dos espaços verdes, a dispersão de imóveis no interior dos espaços de lazer e dos jardins - 40 metros quadrados de espaço verde por habitante no lugar de 12, na antiga Varsóvia - e o crescimento da cidade para cerca de 200.000 habitantes, demandam a constituição de uma rede de comunicação que será uma das novas características da cidade renovada, com a substituição progressiva dos ônibus, dos trólebus e do metrô, no lugar das velhas linhas de bondes.

Cerca de dez anos de um trabalho obstinado, começados com os meios técnicos rudimentares, bastaram para fazer de Varsóvia uma nova capital, edificada sob um dos mais impressionantes teatros das destruições da guerra, seguindo um plano racional, desprovido de pressuposições, compatível com o homem e as novas formas de vida nacional. 